\title{
BMJ Open PIM-Check: development of an international prescription-screening checklist designed by a Delphi method for internal medicine patients
}

\author{
Aude Desnoyer, ${ }^{1,2}$ Anne-Laure Blanc, ${ }^{1,3}$ Valérie Pourcher, ${ }^{4,5}$ Marie Besson, ${ }^{6}$ \\ Caroline Fonzo-Christe, ${ }^{1}$ Jules Desmeules, ${ }^{6,7}$ Arnaud Perrier, ${ }^{8}$ Pascal Bonnabry, ${ }^{1,7}$ \\ Caroline Samer, ${ }^{6}$ Bertrand Guignard ${ }^{1,6}$
}

To cite: Desnoyer A,

Blanc A-L, Pourcher V, et al. PIM-Check: development of an international prescriptionscreening checklist designed by a Delphi method for internal medicine patients. BMJ Open 2017;7:e016070. doi:10.1136/ bmjopen-2017-016070

- Prepublication history and additional material are available. To view these files please visit the journal online (http://dx.doi. org/10.1136/bmjopen-2017016070).

Received 25 January 2017 Revised 21 May 2017 Accepted 6 June 2017

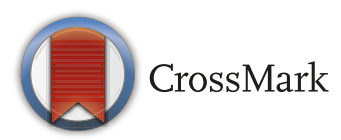

For numbered affiliations see end of article.

Correspondence to

Aude Desnoyer;

audedesnoyer@gmail.com

\section{ABSTRACT}

Objectives Potentially inappropriate medication (PIM) occurs frequently and is a well-known risk factor for adverse drug events, but its incidence is underestimated in internal medicine. The objective of this study was to develop an electronic prescription-screening checklist to assist residents and young healthcare professionals in PIM detection.

Design Five-step study involving selection of medical domains, literature review and 17 semistructured interviews, a two-round Delphi survey, a forward/backtranslation process and an electronic tool development. Setting 22 University and general hospitals from Canada, Belgium, France and Switzerland.

Participants 40 physicians and 25 clinical pharmacists were involved in the study. Agreement with the checklist statements and their usefulness for healthcare professional training were evaluated using two 6-point Likert scales (ranging from 0 to 5).

Primary and secondary outcome measures Agreement and usefulness ratings were defined as: $>65 \%$ of the experts giving the statement a rating of 4 or 5 , during the first Delphi-round and $>75 \%$ during the second.

Results 166 statements were generated during the first two steps. Mean agreement and usefulness ratings were $4.32 / 5$ (95\% Cl 4.28 to 4.36 ) and 4.11/5 (4.07 to 4.15), respectively, during the first Delphi-round and $4.53 / 5$ (4.51 to 4.56 ) and $4.36 / 5$ (4.33 to 4.39 ) during the second $(p<0.001)$. The final checklist includes 160 statements in 17 medical domains and 56 pathologies. An algorithm of approximately 31000 lines was developed including comorbidities and medications variables to create the electronic tool.

Conclusion PIM-Check is the first electronic prescriptionscreening checklist designed to detect PIM in internal medicine. It is intended to help young healthcare professionals in their clinical practice to detect PIM, to reduce medication errors and to improve patient safety.

\section{BACKGROUND}

Improving medication safety and optimising drug prescribing are fundamental to patient safety and are priority goals of healthcare
Strengths and limitations of this study

- A screening checklist for potentially inappropriate medication detection in internal medicine patients was developed by an international and multidisciplinary panel of experts, using a validated consensus method.

- Results from this study should be robust, because the number of experts involved in the Delphi survey and the participation rate were high $(n=40$ experts and $97.5 \%$, respectively) and the reliability of a Delphi survey is directly proportional to the size of the expert group.

- As participants involved in this study came from French-speaking countries, further work will be needed to assess the effectiveness of the English version of the tool in non-French-speaking areas.

systems worldwide. ${ }^{12}$ Drug-related problems (DRPs) defined as an event or circumstance involving a patient's drug treatment that actually or potentially interferes with the achievement of an optimal outcome are common in internal medicine: approximately $80 \%$ of the inpatients have at least 1 DRP, with a mean of 2-3 DRPs per patient. ${ }^{3-7}$ DRPs include subtherapeutic dosage, failure to receive drugs, adverse reactions and potentially inappropriate medication (PIM), defined as the prescribing of medications without a valid indication or with a contraindication (overprescription); failure to prescribe a clinically indicated drug (underprescription); the occurrence of unwanted drug-drug or drug-disease interactions or the incorrect prescribing of an indicated drug (misprescription), such as duplicate prescribing, inappropriate follow-up and incorrect medication dose or duration. ${ }^{8}$ PIM is a well-known risk factor for adverse drug events and is therefore a source of morbidities 
and sometimes mortality, imposing clinical and economic burdens on patients and healthcare systems. ${ }^{9}$

Many prescription-screening checklists, such as the Beers Criteria (North America), ${ }^{10-14}$ the Assessing Care of Vulnerable Elders indicators (United States),${ }^{15} 16$ a set of criteria developed in Australia ${ }^{17}$ and the STOPP/START criteria (Europe), ${ }^{18}{ }^{19}$ have been developed to detect PIM in geriatric patients. ${ }^{80-22}$ Application of STOPP/ START combined with education of physicians and pharmacists has been shown to be effective in minimising PIM in this population. ${ }^{23}$ However, no such checklist has been developed for general internal medicine patients. Nevertheless, multimorbidity and polypharmacy are frequent in this population ${ }^{4-7}$ and are independent risk factors for the occurrence of DRPs, whereas age is not. ${ }^{424}$ Geriatric checklists can be used for patients admitted in internal medicine, but such checklists are often much more focused on geriatric pathologies, not necessarily relevant in internal medicine (eg, dementia and Alzheimer's disease). Some pathologies and interventions commonly encountered in internal medicine are almost never covered by geriatric checklists (eg, obesity, contraception, infectious diseases, transplantation, renal failure and neuropathic pain).

Therefore, we have developed a new international electronic prescription-screening checklist for use with adults in general internal medicine. Specifically, we adapted the approach used by Gallagher $e t a l^{18}$ with the aim of achieving an international, multidisciplinary consensus on a checklist of statements that includes all types of PIMs, covers pathologies commonly observed in internal medicine and is available as an electronic version to assist and train junior healthcare professionals, in PIM detection in their daily practice and to improve medication safety.

\section{METHODS}

This study was split into five steps (figure 1).

\section{First step: Selection of medical domains}

A multidisciplinary international research group consisting of four internists, five clinical pharmacists, and three clinical pharmacologists from France and Switzerland was constituted to supervise the project. The group was responsible for selecting the medical domains (eg, medical specialties and medical acts, such as vaccinations and transplants) and subdomains (including pathologies, therapeutic classes and medical procedures (eg, prevention/prophylaxis, analgesia)) to be addressed in the draft version of the checklist. Selections of medical domains and subdomains were based on the main diseases observed in patients admitted to internal medicine, ${ }^{25}$ the therapeutic classes associated with adverse drug events in these patients, ${ }^{7}$ the Institute for Safe Medication Practices' list of high-alert medications that includes drugs that bear an increased risk of causing significant patient harm when they are used in error ${ }^{26}$ and some of the pathologies included in previously published geriatric prescription-screening checklists. ${ }^{20222527} \mathrm{AD}$ led the project and is the principal investigator in this study.

\section{Second step: Literature reviews, semistructured interviews and draft criteria agreement}

During this step, statements of potential interest for a prescription-screening checklist dedicated to adults

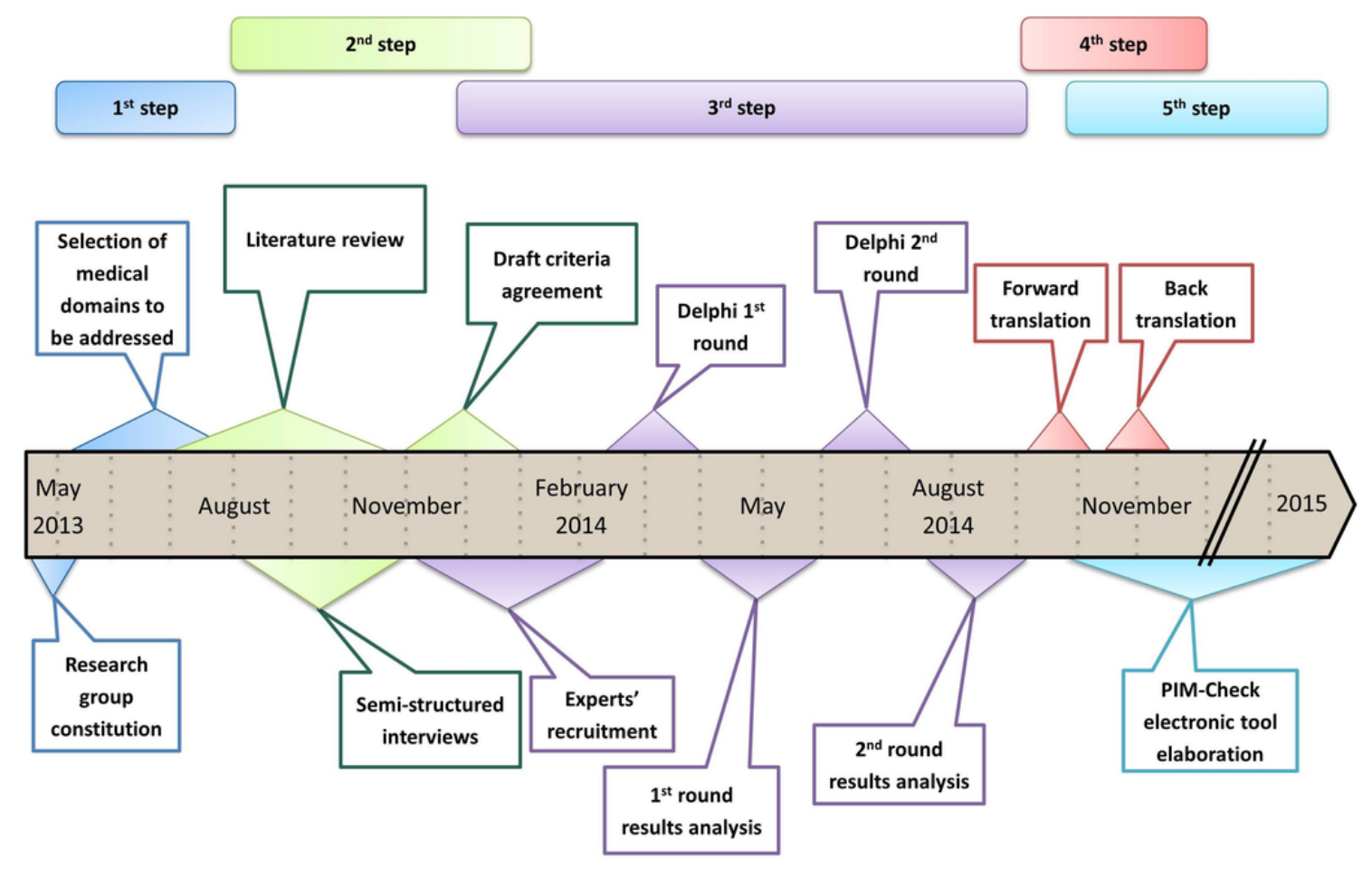

Figure 1 Study workflow. 
in internal medicine (excluding pregnant women and inpatients with low life expectancy or requiring palliative care) were identified and selected for inclusion in the draft checklist.

\section{Literature reviews and semistructured interviews}

For each medical domain and subdomains selected during the first step, an extensive literature review of evidence-based optimal and inappropriate medication prescriptions was conducted. It preceded a semistructured interview, with a specialist physician of the domain to be addressed during the interview, working in the Geneva University Hospitals. The literature review process is detailed in the online supplementary appendix 1 . Each interview comprised four parts: (1) project presentation, (2) presentation of statements previously published in geriatric prescription-screening checklists and statements related to the medical field addressed during the interview, (3) submission to the specialist of the pathologies and statements formulated during the literature review and (4) suggestions by the specialist of pathologies and statements to be added to the draft version. The semistructured interview topics and guide are provided in the online supplementary appendix 1 and supplementary table 1 .

\section{Draft criteria agreement}

After semistructured interviews, redundant statements related to two or more domains and validated by at least two medical specialists were merged and the formulation of each remaining statement was standardised by the principal investigator. Finally, the statements were submitted to five members of the research group-three internists, one clinical pharmacist and one clinical pharmacologist-who anonymously rated the usefulness of the statements for practice in internal medicine by using a 5-point Likert scale ranging from 1 (not useful at all) to 5 (very useful). Statements with a mean rating greater than or equal to 3 were retained for the next step.

\section{Third step: Delphi study}

A two-round Delphi method was used to generate a consensual validation of the statements that were included in the draft checklist (figure 2).

\section{Experts' recruitment}

To represent the views of the professional groups engaged in medication management in internal medicine, a panel of experts in French-speaking countries was recruited in roughly equal numbers by profession (internists and clinical pharmacists with a practice in internal medicine), hospital teaching status (university
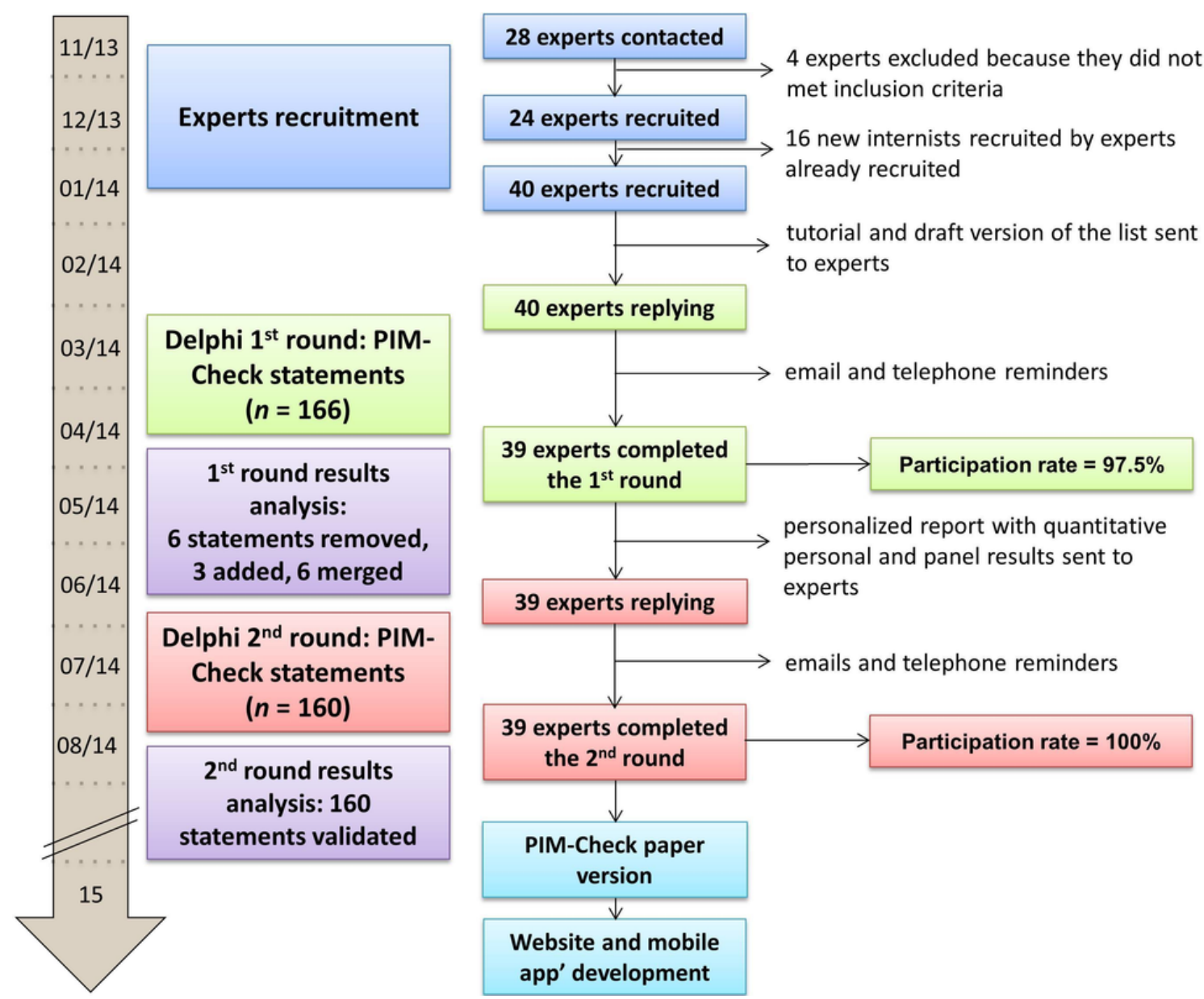

Figure 2 Delphi flowchart. 
and non-teaching hospitals) and country (Canada (Québec), Belgium, France and Switzerland). The recruitment process is described in the online supplementary appendix 1 .

\section{Delphi rounds}

We used the SurveyMonkey website to conduct the Delphi survey. As detailed in the online supplementary appendix 1,1 week before each round, experts received by email the relevant documents to validate statements. For each round, the experts had to indicate their level of agreement with each statement using a 6-point Likert scale: 0 , no opinion; 1 , strongly disagree; 2 , disagree; 3 , neither agree nor disagree; 4 , agree and 5 , strongly agree. Using a second 6-point Likert scale, ranging from 1 (not useful at all) to 5 (very useful) (0, no opinion), the experts also had to rate the usefulness of each statement for daily practice and for training of students, residents and young healthcare professionals in internal medicine or clinical pharmacy. Finally, the experts were invited to add propositions including comments, modifications, references and useful links to each statement.

In accordance with previous studies, we used the following two validation rules. Statements that received the agreement (rating 4 or 5) of more than $65 \%$ of the experts after the first round were retained, were eventually modified according to the experts' comments and were subjected to the second round. ${ }^{28}{ }^{29}$ Statements with a lower percentage of experts' agreement were excluded (ie, $\leq 65 \%$ of the experts rating 4 or 5 the statement). After the second round, only statements that received the agreement of more than $75 \%$ of the experts were retained for the final version of the checklist. The usefulness rating was considered a secondary endpoint and was not used to exclude statements. The expected durations of the first and second rounds were 3 and 2 weeks, respectively. For each round, reminders were sent to the experts, as described in the online supplementary appendix 1.

\section{Integration of experts' propositions}

To reduce potential bias due to a single person doing all the data management, we used investigator triangulation to integrate comments and propositions from the experts. ${ }^{30}$ This triangulation process is detailed in the online supplementary appendix 1.

\section{Fourth step: Forward/back-translation process}

A forward/back-translation process was applied to translate the checklist in English. ${ }^{31}$ Briefly, the checklist was forward-translated into English by a bilingual nativeEnglish-speaking physician from Elsevier Translation Service who was familiar with French-speaking culture and with the terminology of internal medicine. Then, a bilingual native-French-speaking internist back-translated the checklist into French. Finally, three members of the research group identified and resolved any instances of inadequate expression between the back translation and the original version.

\section{Fifth step: Electronic tool development}

To facilitate the use of the tool in daily practice, an electronic version was created. A web-designer and a webmaster were involved in the development of a website and a web-mobile application. A 'Screening' function, allowing to select for a specific patient, his/her comorbidities and/or medications and to present only relevant statements, a 'Favourite' function to give quick access to statements identified as favourite and a 'Learning' function to allow users to follow their progress in the acquisition of recommendation knowledge were included in the application. To develop the 'Screening' function, members of the research group identified medications, and corresponding anatomical therapeutic chemical code, from Belgium, France, Quebec and Switzerland, using national databases. ${ }^{32-35} \mathrm{~A}$ dictionary of synonyms of subdomains included in the tool was also created. Then, an algorithm combining each validated statement with corresponding subdomains and medications was developed.

\section{Statistical methods}

Analyses were performed with Prism 6 software (GraphPad Software, San Diego, California, USA). Variables were summarised as numbers (percentages) for categorical variables, the mean and 95\% CI for continuous variables. During each Delphi round and for each statement, the mean agreement rating, the mean usefulness rating, the percentage of experts who rated each statement as 4 or 5 , the participation rate and the mean number of experts who responded with 'no opinion' (0) were evaluated. For each statement, the mean agreement and usefulness ratings were compared between the first and the second rounds using Mann-Whitney tests. p Values are two-tailed, with a significance level of 0.05 .

\section{Ethics considerations}

The Swiss Law on Medical Research Involving Human Subjects did not require us to seek ethical approval as no participation by patients or use of patients' data, human tissue or animals were involved in this study.

\section{RESULTS}

\section{First and second steps}

The principal investigator conducted 17 semistructured interviews, one each with 17 specialist physicians. Seventeen medical domains and 69 subdomains associated with pathologies, therapeutic classes, medical procedures and DRPs commonly observed in internal medicine were identified. After the semistructured interviews and suppression or merging of redundant statements, 187 statements remained. Among them, 21 mean ratings were less than 3 (2.44 (2.33 to 2.55)) and were considered to be not useful for practice in internal medicine. These statements were excluded from the draft checklist (eg, statements related to sleep apnoea, cystic fibrosis, polymyalgia rheumatica and myasthenia gravis). The remaining 166 statements involved 17 medical domains and 65 
Table 1 Characteristics of Delphi panel of experts

\begin{tabular}{|c|c|}
\hline \multicolumn{2}{|l|}{ Characteristic } \\
\hline Sex: male/female, n (\%) & $23(57.5 \%) / 17(42.5 \%)$ \\
\hline \multicolumn{2}{|l|}{ Profession: n (\%) } \\
\hline Internist & $20(50 \%)$ \\
\hline Clinical pharmacist & $20(50 \%)$ \\
\hline $\begin{array}{l}\text { Years of professional experience: } \\
\text { median }(\mathrm{Cl})\end{array}$ & $9(4-14)$ \\
\hline \multicolumn{2}{|l|}{ Teaching status of hospital: $n$ (\%) } \\
\hline University hospital & $23(57 \%)$ \\
\hline Non-teaching hospital & $17(43 \%)$ \\
\hline \multicolumn{2}{|l|}{ Country of expert: $n(\%)$} \\
\hline Belgium & $9(22.5 \%)$ \\
\hline France & $13(32.5 \%)$ \\
\hline Canada (Québec) & $8(20 \%)$ \\
\hline Switzerland & $10(25 \%)$ \\
\hline
\end{tabular}

subdomains that received a mean usefulness rating of $3.99 / 5$ (3.89 to 4.08$)$.

\section{Third step: Delphi survey}

Forty experts from 22 hospitals met the inclusion criteria and agreed to join the Delphi survey (table 1). During the first round, participation rate was $97.5 \%$ (39/40). A median of 37 (IQR 25\%-75\%: 36-38) experts rated their agreement for each statement, with a median of 2 experts with 'no opinion' per statement. Only one statement was evaluated by fewer than 30 experts $(n=28)$; because this statement completed the first-round validation rule, it was clarified and modified according to the experts' comments and submitted for the second round of Delphi. The mean agreement and usefulness rating were $4.32 / 5$ (95\% CI 4.28 to 4.36 ) and $4.11 / 5$ (4.07 to 4.15 ), respectively according to the 0-5 Likert scales. Six statements were removed according to the validation rule for the first round (table 2). Of the 166 statements evaluated in the first Delphi round, $152(91.5 \%)$ were rated by more than $65 \%$ of the experts as useful or very useful for the training of students, residents and young healthcare professionals in internal medicine and clinical pharmacy. The experts made 677 comments, which led the investigator triangulation group to add 3 new statements, modify 84 , and merge 3 pairs of statements. The remaining 160 statements were retained and subjected to the second round.

All the experts who completed the first round completed the second round (participation rate 100\% $(39 / 39))$. They rated their level of agreement for $100 \%$ of the statements, without selecting the 'no opinion' option. The mean agreement and usefulness ratings were 4.53/5 (95\% CI 4.51 to 4.56 ) and 4.36/5 (4.33 to 4.39), respectively (see online supplementary table 1). Both ratings were higher than the corresponding ratings from the first round $(p<0.001)$. After the second round, all 160 submitted statements were validated according to validation rule for this round. Of these statements, 156 (97.5\%) were rated as useful or very useful by more than $75 \%$ of the experts (see online supplementary table 2). During the second round, the experts made 399 propositions and on the basis of these propositions, 74 statements were clarified.

The final checklist includes 160 statements, divided into 17 medical domains and 52 subdomains (table 3). Seventy-four $(46 \%)$ statements are related to underprescription,

Table 2 Statements rejected by the expert panel during the first round of the Delphi survey

\begin{tabular}{llll} 
Type of PIM & $\begin{array}{l}\text { Medical domain and } \\
\text { subdomain }\end{array}$ & Rejected statement & $\begin{array}{l}\text { Proportion of experts who } \\
\text { agreed or strongly agreed } \\
\text { with the statement (\%) }\end{array}$ \\
\hline Underprescription & $\begin{array}{l}\text { Cardiology: } \\
\text { Dyslipidaemia and } \\
\text { hypolipidemics }\end{array}$ & $\begin{array}{l}\text { Prescribe fibrates as a first-line treatment in } \\
\text { case of isolated hypertriglyceridaemia when } \\
\text { pharmacological treatment is necessary* }\end{array}$ & 56.4 \\
Overprescription & $\begin{array}{l}\text { Pneumology: } \\
\text { Chronic respiratory } \\
\text { diseases }\end{array}$ & $\begin{array}{l}\text { Avoid prescribing BZD or opiates in patients with } \\
\text { chronic respiratory disease when an alternative is } \\
\text { available or monitor respiratory function closely }\end{array}$ & 63.2 \\
\multirow{2}{*}{ Underprescription } & $\begin{array}{l}\text { Nephrology: } \\
\text { Renal failure }\end{array}$ & $\begin{array}{l}\text { Prescribe or continue treatment with statins in } \\
\text { patients with chronic renal failure* }\end{array}$ & 57.1 \\
\hline \multirow{2}{*}{ Other } & $\begin{array}{l}\text { Neurology: } \\
\text { Epilepsy and } \\
\text { antiepileptics }\end{array}$ & $\begin{array}{l}\text { When possible, keep the same antiepileptic brand } \\
\text { name in hospitalised patients or re-evaluate } \\
\text { treatment with a specialist }\end{array}$ & 55.3 \\
\hline \multirow{2}{*}{ Underprescription } & $\begin{array}{l}\text { Psychiatry: } \\
\text { Insomnia, sedatives } \\
\text { and hypnotics }\end{array}$ & $\begin{array}{l}\text { Prescribe BZD or a BZD-like drug as a first- } \\
\text { line treatment in case of insomnia when } \\
\text { pharmacological treatment is necessary }\end{array}$ & 57.9 \\
\hline Overprescription & $\begin{array}{l}\text { Psychiatry: } \\
\text { Insomnia, sedatives } \\
\text { and hypnotics }\end{array}$ & $\begin{array}{l}\text { Avoid prescribing drugs that may exacerbate } \\
\text { insomnia* in patients with chronic insomnia }\end{array}$ & 53.8 \\
\hline
\end{tabular}

${ }^{\star}$ Additional information provided to experts. 
Table 3 Final list of statements included in PIM-Check

\section{PIM-Check: Potentially Inappropriate Medication checklist for Patients in Internal Medicine}

This tool is designed for quick detection of underprescription: UP, overprescription: OP, drug interaction: DDI or other kind of potentially inappropriate medications (eg, therapeutic adaptations, treatment re-evaluations, improper drug use): OTH, that may be dangerous for patients hospitalised in internal medicine (excluding pregnant women and patients with low life expectancy or requiring palliative care).

It is organised by major physiological systems and pathologies.

This is not a replacement for a clinical and biological evaluation by a clinician. The proposals are only applicable in the event there is no patient-specific contraindication.

This tool was validated using a Delphi method including 40 international experts from Belgium, France, Québec and

Switzerland.

Some drugs listed may not be available in each country.

\begin{tabular}{|c|c|}
\hline \multicolumn{2}{|r|}{ CARDIOLOGY } \\
\hline \multicolumn{2}{|r|}{ Heart failure } \\
\hline $\begin{array}{l}1 \\
\text { UP }\end{array}$ & $\begin{array}{l}\text { Start } A C E I \text { or } A R B \\
\text { Prescribe or continue long-term ACEI treatment in patients with } \mathrm{HF} \text { (or ARB in case of intolerance) }\end{array}$ \\
\hline $\begin{array}{l}2 \\
\text { UP }\end{array}$ & $\begin{array}{l}\text { Start beta-blocker treatment } \\
\text { Prescribe or continue long-term beta-blocker treatment* in patients with } \mathrm{HF}\end{array}$ \\
\hline$\stackrel{3}{\mathrm{UP}}$ & $\begin{array}{l}\text { Start aldosterone antagonist when LVEF } \leq 35 \% \text { despite optimal treatment } \\
\text { Consider prescribing an aldosterone antagonist in } \mathrm{HF} \text { patients with } \mathrm{LVEF} \leq 35 \% \text { despite treatment with } \mathrm{ACEI} \text {, or } \\
\text { ARB and beta-blocker at the recommended or maximum tolerated doses }\end{array}$ \\
\hline OP & $\begin{array}{l}\text { Drugs that may exacerbate HF } \\
\text { Avoid prescribing drugs }{ }^{\star} \text { that may exacerbate HF, drugs that are rich in sodium }{ }^{\star *} \text { and antiarrhythmics (except for } \\
\text { digoxin and amiodarone) in HF patients }\end{array}$ \\
\hline
\end{tabular}

\section{Dyslipidaemia and hypolipidemics}

$5 \quad$ Dyslipidaemia and high cardiovascular risk: start statins

UP Prescribe or continue treatment with statins in patients with a high cardiovascular risk or adapt lifestyle and dietary measures and the treatment intensity based on that risk (moderate, high or very high)

6

UP

$7 \quad$ Statins and DDI

Dyslipidaemia, hypercholesterolaemia: start statins as a first-line treatment

UP Prescribe statins as a first-line treatment in case of mixed dyslipidaemia or hypercholesterolaemia when pharmacological treatment is necessary*

DDI

Evaluate the risk of DDIs and adapt the treatment if statins are introduced or if treatment is modified in patients receiving statins

Avoid combining statins and fibrates

Avoid combining statins and fibrates and prohibit the statin/gemfibrozil combination

\section{Stable ischaemic heart disease}

$9 \quad$ Start beta-blocker treatment

UP Prescribe or continue beta-blocker treatment in patients with ischaemic heart disease

$10 \quad$ Start low-dose aspirin

UP

$11 \quad$ Start statins

Prescribe or continue treatment with low-dose aspirin in patients suffering from ischaemic heart disease (when there is no contraindication*)

UP $\quad$ Prescribe or continue statins in patients suffering from stable ischaemic heart disease

\section{Secondary prevention of acute STEMI or NSTEMI}

12 Encourage patients having undergone a STEMI or NSTEMI to participate in a secondary prevention programme,

Other specifically aiming to adapt their diet, control their weight, engage in physical activity, stop smoking and improve compliance with treatment

$13 \quad$ Start beta-blocker treatment

UP Prescribe or continue long-term beta-blocker treatment after a STEMI or NSTEMI

$14 \quad$ Dual antiplatelet therapy?

UP Prescribe or continue treatment by dual antiplatelet therapy for up to 12 months after a STEMI or NSTEMI,

followed by long-term antiplatelet monotherapy (first-line treatment = low-dose aspirin) 


\section{Table 3 Continued}

\section{PIM-Check: Potentially Inappropriate Medication checklist for Patients in Internal Medicine}

15
UP
16
UP

17
UP

Start statins

Prescribe or continue statins after STEMI or NSTEMI

Start ACEI or ARB

Prescribe or continue treatment with ACEI for at least 30 days following a STEMI or NSTEMI and then, on a longterm basis, in particular in the presence of an aggravating factor* (or an ARB in case of intolerance)

\section{High blood pressure}

Start antihypertensive drug treatment

Begin antihypertensive drug treatment with a first-line drug* alone or in combination if pharmacological treatment of BP is necessary ${ }^{\star \star}$. Combine it with lifestyle and diet modifications ${ }^{\star \star \star}$

18 Favour ACEI or ARB in patients with diabetes/CKD/HF/STEMI/NSTEMI and HBP

Other Favour an ACEI or ARB combined or without another first-line antihypertensive drug to treat high BP in patients with diabetes or in patients with microalbuminuria/proteinuria, CKD, HF or history of STEMI or NSTEMI

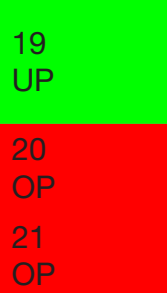

Resistant high BP

Seek a secondary cause of high BP and then optionally add an aldosterone antagonist*, amiloride or an alpha 1 blocker in case of true resistant $\mathrm{HTN}^{* *}$

Drugs that can exacerbate high BP

Exercise caution in using drugs that may increase $\mathrm{BP}^{\star}$ or that are rich in sodium ${ }^{\star *}$ in patients with high $\mathrm{BP}$

Avoid loop diuretic as a first-line treatment

Do not prescribe a loop diuretic as a first-line treatment to treat high BP

$\begin{array}{ll}22 & \text { Start statins } \\ \text { UP } & \text { Prescribe statins in patients with non-cardioembolic and non-haemorrhagic TIA or stroke } \\ 23 & \text { Start antiplatelet therapy } \\ \text { UP } & \begin{array}{l}\text { Prescribe a preventive antiplatelet therapy* in patients with non-cardioembolic and non-haemorrhagic TIA or } \\ \text { stroke }\end{array}\end{array}$

\section{Arrhythmias, atrial fibrillation and antiarrhythmics}

\section{$24 \quad$ Adjust digoxin dose}

Other Reduce or adjust digoxin dose depending on the digoxin serum levels in elderly patients or patients with renal failure; favour an alternative when possible

25
DDI
26
UP

Digoxin and DDIs

Evaluate the risk of DDIs and adapt treatment in case new treatment is introduced in a patient receiving digoxin (in particular with Pgp inhibitors)

Start oral anticoagulation

Prescribe or continue oral anticoagulation* in patients suffering from non-valvular AF whose $\mathrm{CHA}_{2} \mathrm{DS}_{2}-\mathrm{VASc}^{* *}$ is $\geq 1$. In case of treatment with VKA, adapt the doses to obtain an INR between 2 and 3

\section{Anticoagulation: start patient education}

Other Provide patient education for patients receiving oral anticoagulation (or the caregiver)

Anticoagulation: prevent the inappropriate administration of anticoagulant

28 Verify the appropriateness of the administration for an oral anticoagulant taken by a patient (dosage, frequency

Other and time of administration) with the indication, the usual treatment and the prescribed molecule (in particular for DOACs: the number of doses/day and the administration conditions)

VKAs: Vitamin K1 administration

$29 \quad$ Favour the OR in case of VKA overdose requiring the administration of Vitamin K1.

Other Favour low doses (1-5 mg) when there is VKA overdose with no bleeding or minor bleeding but requiring the administration of Vitamin $\mathrm{K} 1$

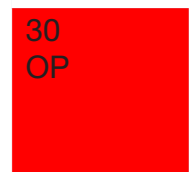

Switching from VKA to DOAC

Consider a DOAC switch in patients who were already treated with VKA only if the INR is not kept in the target zone despite monitoring and correct observance or in case of intolerance. Continue VKA treatment if the latter is effective and well tolerated 


\section{Table 3 Continued}

\section{PIM-Check: Potentially Inappropriate Medication checklist for Patients in Internal Medicine}

31

Other

Anticoagulation and renal function treatment if the $\mathrm{CrCl}$ is $<30 \mathrm{~mL} / \mathrm{min}$

$32 \quad$ Anticoagulation and DDls $\begin{array}{ll}\text { DDI } & \text { Evaluate the risk } \\ \text { anticoagulant }\end{array}$

Deep vein thrombosis, pulmonary embolism, venus thromboembolism

33 DVT/PE: start anticoagulation

UP Prescribe or continue anticoagulation for at least 3 months ${ }^{*}$ in case of proximal DVT and/or PE. In case of treatment with VKA, adapt the doses to obtain an INR between 2 and 3

$34 \quad$ Idiopathic VTE: start anticoagulation

UP Prescribe or continue anticoagulation for at least 3 months or long term with annual re-evaluation in case of idiopathic VTE or with a major persistent risk factor*

DVT/PE/VTE: start prophylactic anticoagulation

$35 \quad$ Prescribe prophylactic anticoagulation* in patients who are hospitalised for acute medical affection for an

UP anticipated duration of $>3$ days and with a high risk of thrombosis ${ }^{\star \star}$ and/or in patients who are hospitalised for surgical procedure with a moderate or high risk of thrombosis

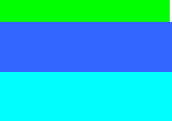

\section{PNEUMOLOGY}

\section{Chronic respiratory diseases}

$36 \quad$ New inhalation drug delivery device: start patient education

Other Provide individualised patient education (or caregiver) if a new inhalation drug delivery device is prescribed and ensure that it is used properly

$37 \quad$ Use of the holding chamber

Other Favour the use of a holding chamber for the administration of products in a metered-dose inhaler in the event of worsening chronic respiratory disease or poor hand-lung coordination

$38 \quad$ ICS mode of administration

Other Favour taking ICS before meals and rinse out the mouth and gargle or brush teeth after inhalation

$39 \quad$ Caution with non-cardioselective beta-blocker

Other Favour a cardioselective beta-blocker* when it is indicated in patients with asthma or COPD

\section{Asthma}

40
UP
41
OP
42
UP

Asthma and long-term treatment: start ICS as a first-line treatment

Prescribe, as a first-line treatment, low-dose ICS in patients with mild persistent asthma* requiring background treatment

Asthma and long-term treatment: avoid long-acting beta2-agonists as a first-line treatment or as monotherapy Do not prescribe as first-line treatment or as monotherapy a long-acting beta2-agonists to treat asthma

Asthma and long-term treatment: add long-acting beta2-agonists as a second-line treatments

Add long-acting beta2-agonists (favoured) or increase the inhaled corticosteroid doses in patients with asthma for whom taking a low dose oflCS alone is not sufficient

\section{Chronic obstructive pulmonary disorder}

$43 \quad$ COPD and long-term treatment: start a beta2-agonist or anticholinergics as a first-line treatment

UP Prescribe an inhaled bronchodilator ( $\beta 2$-mimetic or anticholinergics) as a first-line pharmacological treatment for COPD

COPD and long-term treatment: avoid ICS as a first-line treatment or as a monotherapy

Do not prescribe ICS as a first-line treatment and as a monotherapy to treat COPD

\section{NEPHROLOGY}

\section{Renal failure}

$45 \quad$ Adjust drug doses

Other Adjust drug doses if a new treatment is introduced in a patient with renal failure or in case of a significant modification of renal function 


\section{Table 3 Continued}

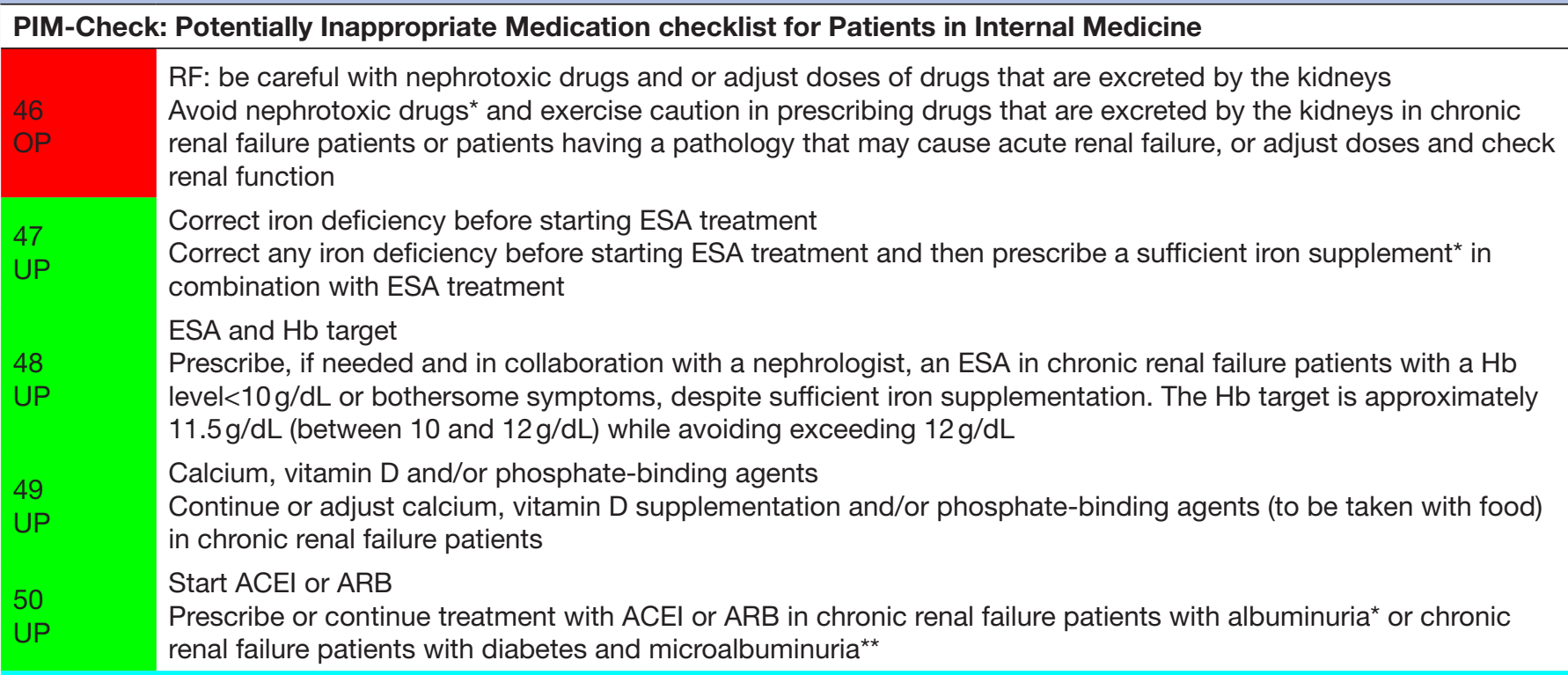
Benign prostatic hyperplasia

Drugs that may exacerbate $\mathrm{BPH}$

Avoid anticholinergic* or sympathomimetic drugs in patients with BPH or use with caution and under monitoring GASTROENTEROLOGY

Peptic ulcer disease and proton pump inhibitors

Peptic ulcer disease prevention: PPI treatment started before hospitalisation

Re-evaluate the continuation of PPI treatment that started more than 8 weeks before hospitalisation

PPI treatment started during hospitalisation

Stop PPI treatment before patient discharge if that treatment started during hospitalisation to prevent bleeding

PPI re-evaluate treatment dose and duration

Do not exceed a dose equivalent ${ }^{\star}$ to $20 \mathrm{mg}$ /day of oral esomeprazole if empiric PPI treatment is started during hospitalisation and do not extend past 8 weeks without gastroenterologist opinion or endoscopic evaluation

PPI: prescription with no valid indication

Do not prescribe a PPI to prevent lesions that are caused by taking NSAIDs, CS or aspirin alone in the absence of a risk factor ${ }^{*}$

Be careful with drugs that may exacerbate ulcer disease

Avoid prescribing drugs that may cause digestive bleeding* in patients suffering from peptic ulcer disease or make sure that it is combined with a PPI

\section{Hepatic impairment and cirrhosis}

Hepatic impairment and cirrhosis: avoid or adjust doses of hepatotoxic drugs or of drugs that are metabolised by the liver

Avoid the use or adjust doses of potentially hepatotoxic drugs or of drugs that are metabolised by the liver* when started in patients with hepatic impairment Hepatic encephalopathy: lactulose and lactitol Consider prescribing disaccharides that are not generally absorbable at high doses in patients suffering from hepatic encephalopathy

\section{Diarrhoea}

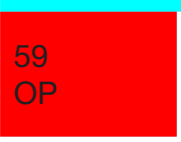

60 Other
Diarrhoea without investigation: avoid antimotility agents

Do not use antimotility agents* in case of mucohaemorrhagic diarrhoea, diarrhoea combined with high fever or postantibiotic diarrhoea without additional investigation

Testing for Clostridium difficile infection

Systematically look for a $C$ difficile infection in case of nosocomial diarrhoea ( $>72$ hour), postantibiotic diarrhoea or diarrhoea with no other aetiology 


\section{PIM-Check: Potentially Inappropriate Medication checklist for Patients in Internal Medicine}

\begin{tabular}{ll}
\hline 61 & Treatment of Clostridium difficile infection \\
UP & Prescribe as a first-line treatment for a first episode of Clostridium difficile infection: \\
& - metronidazole (OR or intravenous), in the case of a mild to moderate episode \\
& vancomycin (OR), in the case of a severe episode
\end{tabular}

\section{Constipation}

Drugs that may exacerbate constipation

Avoid or use with caution drugs that may cause iatrogenic constipation* in patients suffering from constipation, or monitor and treat any aggravation

\section{RHEUMATOLOGY \\ Gout}

63

UP

64

UP

65

UP

$66 \quad$ Drugs that may exacerbate gout

When an alternative is available, avoid or use with caution drugs that may cause an increase in uric acid levels and gout attacks* in patients suffering from gout

\section{Rheumatoid arthritis}

67

Other

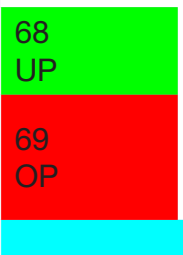

70 Other

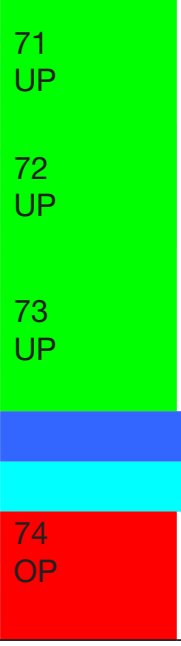

MTX and monitoring

Acute gout: NSAID and/or colchicine or glucocorticoid as a first-line treatment

Prescribe as a first-line treatment an NSAID and/or oral colchicine or even a glucocorticoid* to patients suffering from acute gout

Gout and long-term treatment: start allopurinol as a first-line treatment

Prescribe allopurinol as a first-line treatment to patients for whom pharmacological treatment seeking to reduce uric acid levels is necessary*

Gout and long-term treatment initiation: add an NSAID or low-dose colchicine

To avoid a gout attack, prescribe an NSAID or low-dose colchicine for the titration duration of a hypouricaemic background treatment or if the dose is changed

Monitor hepatic transaminases, complete blood count and renal function before starting treatment with MTX and then regularly during treatment (in particular if combined with other hepatotoxic, haematotoxic or nephrotoxic drugs $^{\star}$ )

MTX: start folic acid

Prescribe preventive treatment with daily or weekly folic acid in patients receiving long-term MTX

Avoid long-term CS

Re-evaluate with a specialist and optionally stop long-term corticosteroid treatment in patients with RA with prolonged remission

\section{Corticosteroids and osteoporosis}

Long-term CS: start patient education

Provide patient education* to those receiving new long-term corticosteroid treatment (or caregivers)

Long-term CS and prevention of osteoporosis: start calcium/vitamin D

Evaluate intake and prescribe calcium and vitamin $D$ if needed to patients receiving corticosteroid treatment for an anticipated duration of $\geq 3$ months (irrespective of the dose)

Long-term CS and prevention of osteoporosis: start bisphosphonates

Prescribe bisphosphonates to patients receiving CS with an increased risk of fracture* or to patients with a high risk of osteoporosis receiving long-term $\mathrm{CS}^{\star *}$

CS and bisphosphonates: prevent inappropriate administration

Correct any hypercalcaemia or vitamin D deficiency* before beginning treatment with bisphosphonates.

Prescribe bisphosphonates in the morning on an empty stomach ${ }^{\star \star}$ with a large glass of lowly mineralised water, separate from other medicines ${ }^{\star \star *}$, informing the patient to remain seated or standing for at least 30 min

\section{Epilepsy and antiepileptics}

Drugs that may exacerbate epilepsy

Avoid or use with caution treatments that may lower the seizure threshold* in an patient with epilepsy if an alternative is available 
Table 3 Continued

\section{PIM-Check: Potentially Inappropriate Medication checklist for Patients in Internal Medicine}

\begin{tabular}{|c|c|}
\hline $\begin{array}{l}75 \\
\text { DDI }\end{array}$ & $\begin{array}{l}\text { Antiepileptic and DDIs } \\
\text { Evaluate the risk of DDIs, and adjust the treatment if a new treatment is introduced in patients receiving } \\
\text { antiepileptics (in particular with CYP and/or Pgp inducers/inhibitors*) }\end{array}$ \\
\hline $\begin{array}{l}76 \\
\text { UP }\end{array}$ & $\begin{array}{l}\text { Antiepileptic and DDls with contraception } \\
\text { Use effective contraception means* if possible other than combined oral or intra-vaginal contraceptives, patches } \\
\text { and pure progestogen pills in women of childbearing age who are treated with an enzyme-inducing anti-epileptic*} \\
\text { and who have not planned to become pregnant }\end{array}$ \\
\hline \multicolumn{2}{|r|}{ Parkinson's disease and Parkinson's medications } \\
\hline $\begin{array}{l}77 \\
\text { UP }\end{array}$ & $\begin{array}{l}\text { Prevent the inappropriate administration of Parkinson's disease treatment } \\
\text { Continue treatment for Parkinson's disease at the usual doses, times and dosing forms in case of hospitalisation. } \\
\text { Adapt the dosing form and the dose in case of fasting or difficulty swallowing }\end{array}$ \\
\hline $\begin{array}{l}78 \\
\text { OP }\end{array}$ & $\begin{array}{l}\text { Parkinson's disease and antinausea neuroleptics: prefer domperidone } \\
\text { Avoid using dopamine antagonist antinausea medications crossing the haematoencephalic barrier to treat nausea } \\
\text { and vomiting in patients with Parkinson's disease. Prefer domperidone }\end{array}$ \\
\hline \multicolumn{2}{|r|}{ PSYCHIATRY } \\
\hline \multicolumn{2}{|r|}{ Psychotropic illness and drugs } \\
\hline $\begin{array}{l}79 \\
\text { OP }\end{array}$ & $\begin{array}{l}\text { Avoid prescribing two psychoactive drugs from the same therapeutic class } \\
\text { Avoid prescribing two psychoactive drugs from the same therapeutic class without seeking a specialised opinion }\end{array}$ \\
\hline \multicolumn{2}{|r|}{ Depression and antidepressants } \\
\hline $\begin{array}{l}80 \\
\text { UP }\end{array}$ & $\begin{array}{l}\text { Optimise the dose of an antidepressant medication if a suboptimal response is observed } \\
\text { Do not stop an insufficiently effective antidepressant treatment before optimising the dose up to the effective do } \\
\text { and verifying patient observance, except in the case of side effects }\end{array}$ \\
\hline $\begin{array}{l}81 \\
\text { UP }\end{array}$ & $\begin{array}{l}\text { Severe depression: start SSRI as a first-line treatment } \\
\text { Prescribe an antidepressant }{ }^{\star} \text { with or without combining psychotherapy in patients suffering from severe } \\
\text { depression }\end{array}$ \\
\hline
\end{tabular}

\section{Insomnia, sedatives and hypnotics}

Hypnotics: Treatment duration and re-evaluation

Re-evaluate hypnotic treatment every 2 weeks and on hospital discharge. Do not stop hypnotic treatment abruptly Hypnotics: drugs to avoid as a first-line treatment

Do not prescribe sedative neuroleptics or antihistamines as a first-line treatment for insomnia (except with specific indications)

\section{Schizophrenia and neuroleptics}

Neuroleptics: Drugs that prolong the QT interval

DDI Avoid prescribing drugs that may prolong the QT interval* in patients receiving a neuroleptic, in particular if their pre-treatment QT interval is long or when there is a risk of torsade de pointes

\section{Neuropathic pain}

$85 \quad$ Neuropathic pain: start an anticonvulsant* or an antidepressant ${ }^{\star \star}$ as a first-line treatment

UP Prescribe as a first-line treatment an anticonvulsant ${ }^{\star}$ or an antidepressant ${ }^{\star \star}$ to treat chronic neuropathic pain requiring pharmacological treatment

$86 \quad$ Neuropathic pain: combine analgesics as a second-line treatment

UP Potentially combine an opiate antalgic with a first-line drug* in case of chronic neuropathic pain after the failure of two monotherapies or a bi-therapy of first-line drugs

\section{Acute pain and opiates}

87 Start opioids in the case of acute moderate to severe pain

UP $\quad$ Prescribe an opiate antalgic in the case of moderate (level 2) to severe (level 3) acute pain, preferably orally, when allowed by the patient's clinical situation (VAS $>4$ according to the WHO scale)

88 Analgesia and opioids: switching and equianalgesic dose ratios

Other Switch opioids ${ }^{\star}$ and apply the rules of equianalgesic dose ratios to determine the initial dose to be administered in patients with side effects, in case of inefficacy despite correct titration, in case of harmful drug interactions or if a change in the administration route is necessary 


\section{Table 3 Continued}

\section{PIM-Check: Potentially Inappropriate Medication checklist for Patients in Internal Medicine}

89

DDI

90

Combine opioids of different release rates

Avoid combining two opioids with the same release kinetics or combining pure agonists-partial agonists

Opioids: start prophylactic measures* to prevent constipation

Take prophylactic measures* to prevent constipation from the start of an opioid treatment

\section{Migraines}

Start a triptan for patients not responding to NSAIDs +/- in combination

Prescribe a triptan in the case of a migraine attack not responding to NSAIDs +/- in combination* or in case of severe migraine

Start migraine prophylaxis

Prescribe a background treatment for migraines in patients with more than two incapacitating migraines/week or very frequently using migraine medication*

\section{INFECTIOLOGY \\ Urinary infections}

Urinary tract infection: replace the urinary catheter before starting antibiotic treatment*

Remove the urinary catheter or change it before starting suitable antibiotic treatment* in patients with urinary infection with a catheter in place for more than 2 weeks

\section{Pulmonary-related and tuberculosis-related infections}

Pneumonia: use beta-lactam, macrolide and/or fluoroquinolone as empirical therapy

Prescribed an antibiotic from the family of beta-lactam, macrolide and/or fluoroquinolone, depending on

the gravity factors and local recommendations, in empirical therapy for community-acquired pneumonia in hospitalised patients

Tuberculosis: treatment for at least $6-18$ months

Continue antituberculosis treatment for at least 6-18 months (depending on the location and the germ) in patients who are treated for active tuberculosis

Anti-tuberculosis drugs: be careful with potentially hepatotoxic drugs*

Avoid or use with caution potentially hepatotoxic drugs* in patients who are treated with antituberculosis drugs, and monitor the hepatic function closely

Rifampicin and DDIs

Evaluate the risk of DDIs and favour the use of drugs not interacting* with rifampicin or adapt treatment in patients treated with rifampicin

\section{Abdominal infections}

Intra-abdominal infection: antibiotics covering anaerobic germs*

Prescribe an antibiotic covering, in particular, anaerobic germs* as an empirical treatment of a serious acute intraabdominal infection

\section{Endocarditis}

Endocarditis prophylaxis: only in patients at very high risk ${ }^{*}$ and undergoing a very high-risk procedure ${ }^{\star *}$

Prescribe preventive endocarditis treatment only in patients at very high risk ${ }^{\star}$ and undergoing a very high-risk procedure $^{\star *}$ for bacterial endocarditis

\section{Osteoarticular infections}

Osteoarticular infection: antibiotics with correct bone penetration*

Prescribe a highly bioavailable antibiotic with correct bone penetration ${ }^{\star}$ that is suitable for the germ and its sensitivity when it is identified during an osteoarticular infection

\section{HIV infection}

HIV infection: HAART and DDIs

Evaluate the risk of DDIs and favour the use of drugs with no interaction with HAART, or adjust the doses if a new treatment is started in patients infected with HIV who are treated with HAART

HIV infection and cardiovascular risk: start statins

Prescribe statins to patients infected with HIV, considering the DDIs. The therapeutic objective in those patients is determined based on their cardiovascular risk level*

\section{Hepatitis $\mathrm{C}$ virus infection}




\section{Table 3 Continued}

\section{PIM-Check: Potentially Inappropriate Medication checklist for Patients in Internal Medicine}

103

DDI

104

Other

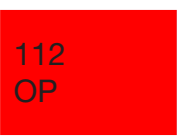

113

Other

\section{5}

Other

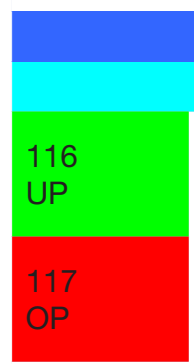

118

Other

HCV infection: direct-acting antivirals against HCV and DDIs

Evaluate the risk of DDIs*, and adapt the treatment if a new treatment is introduced in patients infected with HCV receiving direct-acting antiviral therapy

\section{Hepatitis B virus infection}

HBV infection: do not suspend long-term antiviral therapy

Do not suspend long-term antiviral therapy with nucleosidic analogues in patients who are infected with HBV without an evaluation by a specialist

\section{Prevention/prophylaxis}

Prophylaxis for Pneumocystis jiroveci pneumonia and bone marrow transplant

Prescribe or continue prophylactic treatment against Pneumocystis pneumonia in patients having received a bone marrow transplant

Prophylaxis for $P$ jiroveci pneumonia and solid organ transplant

Prescribe or continue prophylactic treatment against Pneumocystis pneumonia in patients having received a solid organ transplant and receiving immunosuppressants

Prophylaxis for $P$ jiroveci pneumonia and HIV infection

Prescribe or continue prophylactic treatment against Pneumocystis pneumonia in patients who are HIV-infected with a CD4 count of $<200$ cells/mm3

Prophylaxis for $P$ jiroveci pneumonia and highly immunosuppressive drugs

Consider prophylactic treatment against Pneumocystis pneumonia in patients receiving highly immunosuppressive treatments*

Isoniazid and the prevention of peripheral neuropathy: start vitamin B6

Prescribe a vitamin B6 supplement in patients who are treated with isoniazid and with a risk of deficiency* or showing signs of peripheral neuropathy

\section{Proper use of antibiotics}

Re-evaluate empiric antibiotic treatment within 24-72 hours

Re-evaluate empiric antibiotic treatment within 24-72 hours after it is started and adapt it based on the patient's clinical condition and the results of bacteriological samples

Antibiotics through parenteral route: re-evaluate the route of administration

Favour the $\mathrm{OR}^{\star}$ as soon as the patient's clinical condition allows it, considering the bacteriological documentation and choosing an antibiotic with good oral bioavailability*

Proper use of antibiotics: re-evaluate the duration of therapy

Re-evaluate the continuation of effective antibiotic treatment after 5-7 days. Continuation of the treatment past

10 days should be reserved for certain serious infections or situations*

Aminoglycoside and vancomycin: therapeutic drug monitoring

Monitor plasma concentrations for antibiotics with a dose-dependent toxicity in the case of suspicion of toxicity or risk situation for toxicity ${ }^{\star *}$ and/or in the case of risk of underdosing ${ }^{\star *}$. Then, adjust the dosing regimens

Macrolides and long QT syndrome or drugs that prolong the QT interval

Exercise caution when using macrolides, in particular azithromycin, in patients with a high cardiovascular risk*, especially if combined with drugs with the potential to cause QT prolongation

Aminoglycosides and once-daily dosing

Preferably use an aminoglycoside with a once-daily dosing regimen by intravenous route (30 min perfusion) combined with another antibiotic and for a duration of $\leq 5$ days (unless there is a particular situation*)

\section{ENDOCRINOLOGY}

\section{Diabetes mellitus}

DM: adjust therapy according to $\mathrm{HbA} 1 \mathrm{c}$ targets

Adjust the antidiabetic treatment in a customised manner, optionally combining several molecules, to obtain a HBA1c target that is adapted to the patient*

DM: avoid drugs that may alter the blood glucose level ${ }^{*}$

Exercise caution in using drugs that may alter the blood glucose level ${ }^{\star \star}$ in patients with diabetes and perform a close monitoring of blood glucose* in case of use

DM: CS and blood glucose monitoring

Monitor blood glucose closely if CS are introduced to patients with diabetes or patients with glucose intolerance, and optionally adjust the antidiabetic treatment 
Table 3 Continued

PIM-Check: Potentially Inappropriate Medication checklist for Patients in Internal Medicine

119

Other

120
UP
121
UP
122
UP
123
OP

DM or microalbuminuria*/proteinuria and HTN: start ACEI or ARB (nephroprotective effects)

Favour an ACEI or ARB combined or not with another first-line antihypertensive drug to treat HTN in patients with diabetes or patients with microalbuminuria*/proteinuria

DM: start statins in patients with a high or very high cardiovascular risk

Prescribe or continue statins in patients with diabetes with a high or very high cardiovascular risk*

DM: start low-dose aspirin in patients with a high cardiovascular risk or as secondary prevention

Consider a low-dose aspirin treatment* in patients with diabetes with a high cardiovascular risk ${ }^{\star \star}$. Prescribe it as secondary prevention of cardiovascular events

T2DM: start metformin as a first-line treatment

Prescribe metformin as a first-line treatment for pharmacological treatment for T2DM

T2DM and metformin: withhold metformin in unstable conditions

If necessary, withhold metformin in hospitalised patients with diabetes in unstable conditions, in case of surgery or in case of the injection of an iodine contrast product, particularly with polymorbidity or renal failure

T2DM and sulfonylurea: monitor blood glucose in unstable conditions

$124 \quad$ Monitor blood glucose closely in the case of treatment using sulfonylurea* in hospitalised patients with diabetes

Other with unstable conditions (particularly in the case of renal failure, frequent hypoglycaemia or difficulties perceiving the signs of hypoglycaemia)

$125 \quad$ DM and renal failure: adjust the doses of antidiabetics

Other Monitor blood glucose and adjust the doses of antidiabetics* in the case of impaired renal function

Thyroid disorders

126 Hypothyroidism: measure the serum TSH 6 weeks after changing the levothyroxine dose

Other Measure the serum TSH 6 weeks after changing the levothyroxine dose or after any change in a levothyroxinebased agent and assess whether a new titration of the dose is necessary

Hypothyroidism: levothyroxine and usual mode of administration

127 Continue treatment with levothyroxine under the usual mode of administration. In the case of initiation, favour

Other the administration on an empty stomach in the morning ${ }^{\star}$ in the absence of substances that may decrease its absorption $^{\star *}$

128
OP
129
OP
130
UP

Hypothyroidism: levothyroxine and OR unavailable

It is not necessary to administer levothyroxine parenterally to dysthyroidal patients with stable euthyroidism who are unable to receive oral treatment for an anticipated duration of $<7$ days

Thyroid disorders: be careful with drugs that may induce hypothyroidism or hyperthyroidism*

Monitor the TSH before and 6 weeks after the introduction of a treatment that may induce thyroid disorders*

Hyperthyroidism: start a beta-blocker

Consider prescribing a beta-blocker in patients with hyperthyroidism, particularly at the beginning of

pharmacological management

\section{Contraception}

$131 \quad$ Contraception and DDls

DDI Verify contraceptive use in all hospitalised women of childbearing age, and if necessary monitor the lack of DDI with the treatments* that are received or started during hospitalisation

\section{OPHTHALMOLOGY \\ Glaucoma}

132

UP

Glaucoma and medication history at admission: continue ophthalmic drop treatment

Verify ophthalmic drop intake during drug medication history at admission and continue glaucoma treatment in patients who are treated for that indication

Acute angle-closure glaucoma: drugs that may exacerbate acute glaucoma

Avoid the use of drugs that may induce acute closed-angle glaucoma* in at-risk individuals who have not had an iridotomy

\section{DEPENDENCIES}

\section{Addictions and hospitalisation}

$134 \quad$ Addiction: rapid interview and brief intervention

Other Perform a rapid interview to detect addiction if an addiction problem is suspected, and if needed, perform a brief intervention to address the addiction problem 
Table 3 Continued

PIM-Check: Potentially Inappropriate Medication checklist for Patients in Internal Medicine

\section{Alcohol dependence}

135 Alcohol dependence: rapid identification test for alcohol dependence and brief intervention

Other In case of suspicion, perform a rapid identification test for alcohol dependence in hospitalised patients

Alcohol withdrawal: start close monitoring and optional prophylaxis with a BZD*

136

Provide close monitoring using a predictive evolution scale and optionally prescribe an appropriate oral BZD* in hospitalised patients with a risk of alcohol withdrawal. If close monitoring is not feasible, prescribe an appropriate oral BZD*

Prescribe treatment with vitamin B1 in alcohol-dependent patients and multivitamins in case of malnutrition

\section{Tobacco use and tobacco withdrawal}

138 Tobacco dependence: start nicotine replacement therapy if needed

UP

139

If needed, prescribe treatment with a nicotine replacement therapy for hospitalised smokers

Tobacco dependence and chronic ischaemic heart disease/respiratory diseases: start smoking cessation intervention

Offer assistance for tobacco cessation to any patient suffering from ischaemic heart disease or chronic respiratory disease

\section{Benzodiazepine dependence}

BZD dependence: continue BZD treatment at the usual dose during the acute phase of hospitalisation Continue BZD treatment at the usual dose for hospitalised patients with BZD dependency. Suggest a progressive tapering out of the acute phase of hospitalisation

\section{Opioid dependence}

$141 \quad$ Opioid dependence: continue maintenance opioid substitution dose equivalence, in hospitalised patients with an opioid dependency and receiving a substitution treatment

Opioid dependence and buprenorphine: be careful when prescribing opioid analgesics

Avoid or be careful when prescribing methadone or a step 2 or 3 opioid analgesic in patients receiving buprenorphine substitution

\section{Proper use of drugs in the case of obesity}

143 Obese patients: increase doses of injectable antithrombotic agents (LMWH/heparin/fondaparinux)

Other Increase the doses of heparin or fondaparinux in obese patients requiring antithrombotic treatment

$144 \quad$ Obese patients: prefer oral and intravenous routes

Other Favour the oral and intravenous routes in obese patients when they are appropriate for the patient and the drug

$145 \quad$ Obese patients: Adjust initial doses of aminoglycosides according to the adjusted body weight*

Other Adjust the initial dose of aminoglycosides in obese patients according to the adjusted body weight* and then reevaluate the dose based on the plasma concentrations

$146 \quad$ Obese patients: Adjust the initial doses of vancomycin according to the total body weight

Other Adjust the initial dose of vancomycin in obese patients according to the total body weight and then re-evaluate the dose based on the plasma concentrations

147
OP
148
OP
149
DDI
150
OP

\section{PHARMACOLOGY and TOXICOLOGY}

Clinical pharmacology

Allergies and new medication: rule out allergies

Verify the absence of allergies when a new medication is introduced in patients

QT prolongation: drugs that prolong the QT interval

Avoid the use of drugs* that may prolong the QT interval in patients suffering from congenital long QT syndrome or at risk of torsade de pointes**

Serotonin syndrome: drugs that are associated with serotonin syndrome

Avoid prescribing two drugs that may induce serotonin syndrome* when an alternative is available or monitor patients closely

Drug-induced Parkinsonism: drugs that may induce extrapyramidal symptoms

Avoid prescribing drugs that may induce extrapyramidal symptoms in patients with that syndrome 


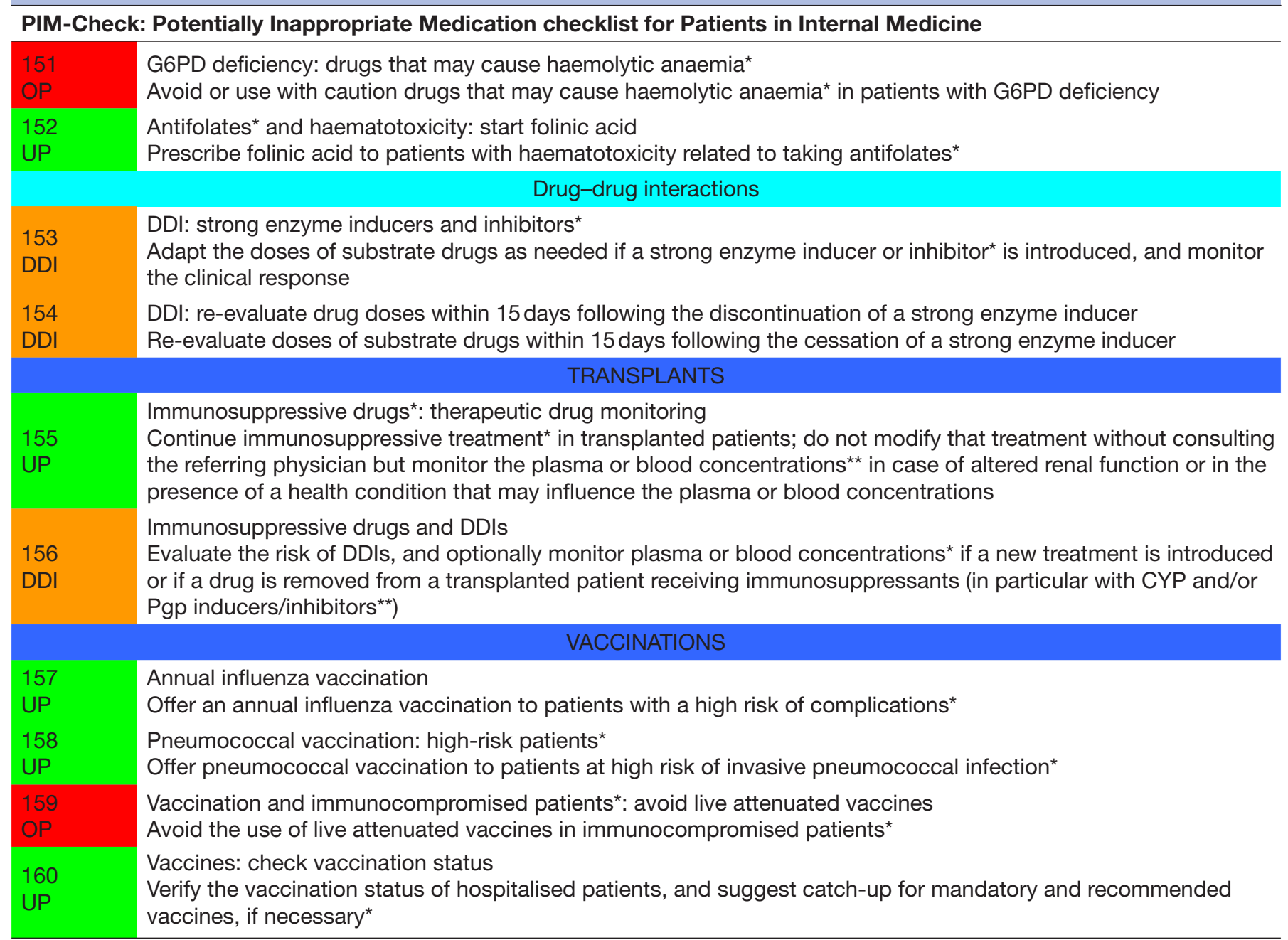

Colour code of PIM: green stands for UPs, red for OPs, amber for DDIs and grey for other kind of PIM.

${ }^{*},{ }^{* *},{ }^{* * *}$ Stars refers to information that is available in online supplementary table 2.

$\mathrm{ACEl}$, angiotensin conversion enzyme inhibitors; AF, atrial fibrillation; ARB, angiotensin II receptor antagonists; $\mathrm{BP}$, blood pressure;

$\mathrm{BPH}$, benign prostatic hyperplasia; BZD, benzodiazepine; CKD, chronic kidney disease; COPD, chronic obstructive pulmonary disorder; $\mathrm{CrCl}$, creatinine clearance; CS, corticosteroids; CYP, cytochrome P450; DDI, drug-drug interaction; DOAC, direct-acting oral anticoagulant; DM, diabetes mellitus; DVT, deep vein thrombosis; ESA, erythropoiesis-stimulating agent; G6PD: glucose-6-phosphate dehydrogenase; GDU, gastroduodenal ulcer; HAART, highly active antiretroviral therapy; Hb, haemoglobin; HBA1c, glycated haemoglobin; HBV, hepatitis B virus; HCV: hepatitis C virus; HF, heart failure; HTN, hypertension; ICS, inhaled corticosteroids; INR:, international normalised ratio; LVEF, left ventricular ejection fraction; MTX, methotrexate; NSAIDs, non-steroidal anti-inflammatory drug; OP, overprescription; OR, oral route; PE, pulmonary embolism; Pgp, P-glycoprotein, PPIs, proton pump inhibitors; RA, rheumatoid arthritis; STEMI, ST-segment elevation myocardial infarction; TIA, transient ischaemic attack; TSH, thyroid-stimulating hormone; T2DM, type 2 diabetes mellitus; UP, underprescription; VAS, visual analogue scale; Vitamin B1, thiamine; Vitamin B6, pyridoxine; VKA, vitamin K antagonist; VTE, venous thromboembolism.

$36(23 \%)$ to overprescription, $16(10 \%)$ to interactions and $34(21 \%)$ to other PIM (eg, insufficient drug monitoring, incorrect dose adjustment, wrong choice of medication). The rationales for the statements are presented in online supplementary table 2, along with 233 references, 116 recommendations (eg, dose adjustment, alternatives and monitoring), 93 remarks (eg, definitions, reminders and useful lists of drugs) and 24 useful web links.

\section{Fourth step: Forward/back-translation}

Among the 160 statements that were forward/back-translated, 16 were identified as having inadequate expression and were then corrected. The tool is available, both in
French and in English (http://app.pimcheck.org/\#/ accueil/en).

\section{Fifth step: electronic tool development}

One hundred and ninety-three synonyms of the 52 subdomains included in the tool and 1635 medications were identified. To create the 'Screening' function, each statement was associated with corresponding subdomains and medications and an algorithm of approximately 31000 lines was developed. This algorithm allows to 'switch on', or 'switch off', statements, depending on comorbidities and medications selected by the user. The 'Favourites' function created gives quick access to statements identified as 
favourite, and the 'Learning' function gives access to the list of all statements included in PIM-Check, those unread and those already read. Details regarding the conception of the tool, direct access to the references $(n=333)$ and useful links $(\mathrm{n}=29)$ (through URL links), publications related to the tool and a contact section, are also available (http://www.pimcheck.org/en/).

\section{Interpretation}

PIM-Check was specifically designed to assist residents and young healthcare professionals in the detection of PIM in patients typically admitted in internal medicine (excluding pregnant women, patients with low life expectancy and patients requiring palliative care). The checklist consists of 160 statements for pathologies and drugs commonly encountered in internal medicine. The checklist does not replace the judgement of physicians and pharmacists but is intended to help young healthcare professionals to improve the medication review process and to reduce the incidence of PIM. Owing to the additional data and references associated with the statements, PIM-Check should also be helpful for training students and residents in prescribing-optimisation. Because most of the statements are based on current international clinical evidence and were validated by European and North American experts, we expect that the English version of PIM-Check will be useful in many healthcare settings. Finally, the availability of an electronic version should facilitate the use of PIM-Check in daily practice.

\section{Comparison with other studies}

PIM-Check includes more medical domains $(n=17)$ and subdomains $(n=52)$ than do the published geriatric checklists. ${ }^{20}$ Some of the domains and subdomains commonly found in geriatric checklists are not included in PIM-Check (eg, falls, dementia, orthostatic hypotension and sleep apnoea). In contrast, PIM-Check includes statements related to domains, such as transplantation, dependencies, obesity, antiviral therapy and proper use of antibiotics that are not generally covered by geriatric checklists. This last domain should be useful because interventions implemented in hospitals to improve the use of antibiotics have succeeded in preventing PIM. ${ }^{36}$ PIM-Check also includes therapeutic classes and drugs commonly associated with preventable hospitalisation and with PIM in internal medicine (eg, non-steroidal anti-inflammatory drugs, anticoagulants, antihypertensive or antidiabetic treatments, statins, proton pump inhibitors and corticosteroids). ${ }^{7} 3738$ PIM-Check is also more focused on underprescription than are geriatric checklists. Seventy-four $(46 \%)$ statements in PIM-Check are related to underprescription versus 18 (37\%), 34 $(27 \%)$ and $71(18 \%)$ in the Australian checklist, STOPP/ START v2, and Assessing Care of Vulnerable Elders indicators v3, respectively. ${ }^{161719}$ This can be explained by the fact that recommending preventive treatment in older populations is sometimes inappropriate. In contrast, underprescription in internal medicine patients is not rare, and occurred 1.8 times as often as overprescription ${ }^{7}$; thus, PIM-Check should be more helpful than other checklists for preventing PIM in this population.

\section{Strengths and limitations}

The Delphi method is a robust method for reaching a consensus of opinion and is commonly used for validating PIM checklists. ${ }^{14} 192029$ The reliability of a Delphi survey is directly proportional to the size of the expert group. ${ }^{39}$ Therefore, we are confident that results from this study are robust, because the number of experts involved in our Delphi survey was high, as was the participation rate. As previously demonstrated by Chang et al, checklists with higher numbers of statements, therapeutic classes and medical domains tend to show higher rates of PIM detection, although the use of long checklists can be time-consuming. ${ }^{21}$ However, PIM-Check is the first checklist available as an electronic device. The 'Screening' function allows users to perform an analysis for a specific patient, restricting the statements displayed to those that are most relevant to that patient, depending on his/her comorbidities and prescribed medications. This function should enable users to review a prescription in less than $5 \mathrm{~min}$, as can be done with STOPP/START. ${ }^{93740}$ However, these issues need to be addressed in the future, as the ability of PIM-Check to prevent PIM.

\section{Implications for clinicians and policymakers}

In our study, experts rated the statements as being highly useful for the training of students and residents. The inclusion of additional data and references with the statements can be expected to make PIM-Check helpful for improving trainee awareness of good prescription practices. Moreover, as previously demonstrated, interactive techniques in medication education and training in the use of systematic tool to reduce PIM are effective in improving prescribing-skill and patient care. ${ }^{41} 42$ The progressive learning function included in the electronic version of PIM-Check may constitute an effective intervention to improve prescribing performance. Finally, PIM-Check could be helpful for researchers and policymakers because it could be used to estimate the incidence of PIM in various settings, to evaluate prescription quality and safety and to evaluate factors and costs associated with PIM, as it has been proposed for STOPP/START and the Beers Criteria. ${ }^{943-48}$

\section{Unanswered questions and future research}

The next step will be to evaluate the incidence of PIM detected and prevented using PIM-Check in various healthcare settings. It will also be of interest to determine whether the use of PIM-Check, like the use of STOPP/ START, is significantly associated with reductions in adverse drug events and improvement in young healthcare professionals prescribing training. ${ }^{23}{ }^{40} 49$ We will test the English version of PIM-Check in non-French-speaking countries. ${ }^{50}$ Another project might be to integrate PIM-Check as a clinical decision support system in electronic health records, to assist physicians and pharmacists in their clinical practice. Finally, like geriatric checklists, ${ }^{10-14} 16181951$ PIM-Check will need to be updated in a 
few years as new research is published and new drugs are licensed.

\section{CONCLUSION}

In conclusion, this study offers an electronic prescription-screening checklist, including 160 statements. The application of this checklist combined with clinical judgement should contribute to help young physicians and pharmacists in their training and clinical practice, to detect and reduce PIM. In the context of expansion of the prevalence of multimorbidity and polypharmacy, PIM-Check could be a complementary strategy to reduce PIM and to improve patient safety.

\section{Author affiliations}

${ }^{1}$ Department of Pharmacy, Hôpitaux Universitaires de Genève, Geneva, Switzerland

${ }^{2}$ Department of Pharmacy, Assistance Publique-Hôpitaux de Paris, Groupe

Hospitalier Pitié-Salpêtrière, Paris, France

${ }^{3}$ Department of Pharmacy, Hôpitaux de l'Est Lémanique, Vevey, Switzerland

${ }^{4}$ Department of Infectious and Tropical Diseases, Assistance Publique-Hôpitaux de Paris, Groupe Hospitalier Pitié-Salpêtrière, Paris, France

${ }^{5}$ UMR996-Inflammation, Chemokines and Immunopathology, Inserm, Clamart, France

${ }^{6}$ Department of Clinical Pharmacology and Toxicology, Hôpitaux Universitaires de Genève, Geneva, Switzerland

${ }^{7}$ Section of Pharmaceutical Sciences, Université de Genève, Université de Lausanne, Geneva, Switzerland

${ }^{8}$ Department of General Internal Medicine, Hôpitaux Universitaires de Genève, Geneva, Switzerland

Acknowledgements The following people constituted the research group in charge of thestudy design: $A D, B G, A L B, V P, M B, C F C, J D, A P$, CS, and PB. $A D, A L B, V P, M B, C F C, B G$, and PB wereresponsible for the selection of the medical domains and subdomains to beaddressed in PIM-Check. We are grateful to the following medicalspecialists from the Hôpitaux Universitaires de Genève for theirindividual contributions to the semi-structured interviews: Victor Bancila(psychiatry), Philippe Bichard (gastroenterology), Françoise Boehlen(haematology and haemostasis), Sandra Boehncke (endocrinology), Yassine Bouatou (nephrology), JD (clinical pharmacology and pain clinic),Georg Ehret (cardiology), Stefan Harbarth (infectious diseases), Jean-PaulJanssens (pneumology), Loïc Locatelli (psychiatry and addictology),Philippe Meyer (cardiology and hypertension), Michael Nissen(rheumatology), Zoltan Pataky (obesity), CS (clinical pharmacology), TarekShaarawy (ophthalmology), Catherine Stoermann (nephrology), and Serge Vulliemoz(neurology). ALB,VP, MB, Olivier Grosgurin (HUG, Geneva,Switzerland) and Christophe Marti (HUG, Geneva, Switzerland) were involved inthe selection of statements before the first round of the Delphi survey. Wethank the Delphi panel of experts: Annie Athouel (pharmacy, Le Mans,France), Aurélie Barrail-Tran (pharmacy, K. Bicêtre, France), OlivierBerclaz (internal medicine, Valais romand, Switzerland), GuyBeuken (general internal medicine, Louvain, Belgium), Dorine Castillo(pharmacy, Macon, France), Remy Charette (pharmacy, McGill, Canada),Delphine Chenevier (pharmacy, Cognac, France), Emmanuelle Dernis(general internal medicine, Le Mans, France), Maxime Dore (pharmacy,Sacré-Coeur, Canada), Guillaume Faubert (pharmacy, MaisonneuveRosemont,Canada), Séverine Foucher (pharmacy, A. Béclère, France), Antoine Garnier(internal medicine, CHUV, Switzerland), Nathalie Gillard (pharmacy,Saint-Kuc, Belgium), BG, Pascal Guillemin (internal medicine, Macon,France), Bernard Hanson (internal medicine, IRIS Sud, Belgium), Ly Khuê(internal medicine, McGill, Canada), Pierre-Olivier Lang (internal medicine,Genolier, Switzerland), Anne-Marie Mansour (internal medicine, Sacré-Coeur,Canada), Ariane Mouzon (pharmacy, Mont-Godinne, Belgium), Carole Nachar(pharmacy, CHUV, Switzerland), Jean-Baptiste Nicolas (internal medicine,Mont-Godinne, Belgium), Nicolas Noel (internal medicine, K. Bicêtre, France),Pauline Papin (pharmacy, Saint Jean, Belgium), Marc Parent (pharmacy, Québec,Canada), Julie Peeterbroeck (pharmacy, A. Vésale, Belgium), Rachel Pham(pharmacy, IRIS Sud, Belgium), Fior Renato (internal medicine, A. Béclère,France), Thibaut Richard (internal medicine, A. Vésale, Belgium), ThierryRomanet (pharmacy, Grenoble, France), Nicolas Schaad (pharmacy, Morges,Switzerland), Mathieu Sergerie (internal medicine, Maisonneuve-Rosemont,Canada), Ionela Stifii (internal medicine, Le Cognac, France), JéromeStirnemann (internal medicine, HUG, Switzerland), Pierre-Alain Triverio (internalmedicine, Jura bernois, Switzerland), Vera Vongunten (pharmacy, Valais romand,Switzerland), Joel Wermeille (pharmacy, Jura bernois, Switzerland), ClaireWintenberger (internal medicine, Grenoble, France), Philippe Zaoui (generalinternal medicine, Grenoble, France). ALB, VP and MB made up the investigator triangulationgroup. We thank Elsevier Translation Service for the forward translationof PIM-Check. CS, AD, BG, and ALB participated in the back translation. Wethank Rolf Hauri (Geneva School of Business Administration (HEG)) andAlain Lorentz (for the web development and the web designing of PIM-Check website andwebmobile application and Carlotta Shearson (Shearson Editorial Services) forediting the manuscript.

Contributors All authors constituted the research group in charge of the design of the study and contributed to the conception of the work. AD, ALB, VP, MB, CFC, BG and $\mathrm{PB}$ were responsible for the selection of the medical domains and subdomains to be addressed in PIM-Check. ALB, VP and MB made up the investigator triangulation group. CS, $A D, B G$ and $A L B$ participated in the back translation of the tool. $A D, P B$ and $B G$ were responsible for the acquisition, analysis and interpretation of data for the work. AD, ALB, PB and BG drafted the work. VP, MB, CFC, JD, AP and CS revised it critically for important intellectual content. All authors approved the final version of the paper to be published and agreed to be accountable for all aspects of the work in ensuring that questions related to the accuracy or integrity of any part of the work are appropriately investigated and resolved.

Competing interests None declared.

Provenance and peer review Not commissioned; externally peer reviewed.

Data sharing statement Full dataset are available with open access at www. pimcheck.org/en/ or from the corresponding author at audedesnoyer@gmail.com.

Open Access This is an Open Access article distributed in accordance with the Creative Commons Attribution Non Commercial (CC BY-NC 4.0) license, which permits others to distribute, remix, adapt, build upon this work non-commercially, and license their derivative works on different terms, provided the original work is properly cited and the use is non-commercial. See: http://creativecommons.org/ licenses/by-nc/4.0/

(C) Article author(s) (or their employer(s) unless otherwise stated in the text of the article) 2017. All rights reserved. No commercial use is permitted unless otherwise expressly granted.

\section{REFERENCES}

1. IMS Institute for Healthcare Informatics. Advancing the responsible use of medicines - Applying levers for change. 2012. http:// www.imshealth.com/en/thought-leadership/ims-institute/reports/ responsible-use-of-medicines-report (assessed 17 Jan 2017).

2. International Pharmaceutical Federation. FIP Statement of professional standards medication errors associated with prescribed medication,available. 1999. http://www.fip.org/www/uploads/ database_file.php?id=229\&table_id= (accessed 17 Jan 2017).

3. Hepler CD, Strand LM. Opportunities and responsibilities in pharmaceutical care. Am J Hosp Pharm 1990;47:533-43.

4. Blix HS, Viktil KK, Reikvam A, et al. The majority of hospitalised patients have drug-related problems: results from a prospective study in general hospitals. Eur J Clin Pharmacol 2004;60:651-8.

5. Blix HS, Viktil KK, Moger TA, et al. Characteristics of drug-related problems discussed by hospital pharmacists in multidisciplinary teams. Pharm World Sci 2006;28:152-8.

6. Bondesson A, Eriksson T, Kragh A, et al. In-hospital medication reviews reduce unidentified drug-related problems. Eur J Clin Pharmacol 2013;69:647-55.

7. Guignard B, Bonnabry P, Perrier A, et al. Drug-related problems identification in general internal medicine: the impact and role of the clinical pharmacist and pharmacologist. Eur J Intern Med 2015;26:399-406.

8. Spinewine A, Schmader KE, Barber N, et al. Appropriate prescribing in elderly people: how well can it be measured and optimised? Lancet 2007;370:173-84.

9. Hill-Taylor B, Sketris I, Hayden J, et al. Application of the STOPP/START criteria: a systematic review of the prevalence of potentially inappropriate prescribing in older adults, and evidence of clinical, humanistic and economic impact. J Clin Pharm Ther 2013;38:360-72.

10. Beers $\mathrm{MH}$, Ouslander JG, Rollingher I, et al. Explicit criteria for determining inappropriate medication use in nursing home 
residents. UCLA Division of Geriatric Medicine. Arch Intern Med 1991:151:1825-32.

11. Beers $\mathrm{MH}$. Explicit criteria for determining potentially inappropriate medication use by the elderly. an update. Arch Intern Med 1997; 157:1531-6.

12. Fick DM, Cooper JW, Wade WE, et al. Updating the Beers criteria for potentially inappropriate medication use in older adults: results of a US consensus panel of experts. Arch Intern Med 2003;163:2716-24.

13. American Geriatrics Society Beers Criteria Update Expert $P$. American Geriatrics Society updated Beers Criteria for potentially inappropriate medication use in older adults. J Am Geriatr Soc 2012;60:616-31.

14. By the American Geriatrics Society Beers Criteria Update Expert P. American Geriatrics Society 2015 Updated Beers Criteria for potentially Inappropriate medication use in Older adults. J Am Geriatr Soc 2015;63:2227-46.

15. Wenger NS, Shekelle PG. Assessing care of vulnerable elders: acove project overview. Ann Intern Med 2001;135:642-6.

16. Wenger NS, Roth CP, Shekelle P, et al. Introduction to the assessing care of vulnerable elders-3 quality Indicator measurement set. J Am Geriatr Soc 2007;55(Suppl 2):S247-S252.

17. Basger BJ, Chen TF, Moles RJ. Validation of prescribing appropriateness criteria for older Australians using the RAND/UCLA appropriateness method. BMJ Open 2012;2:e001431.

18. Gallagher P, Ryan C, Byrne S, et al. STOPP (Screening Tool of Older person's Prescriptions) and START (Screening Tool to Alert doctors to Right Treatment). Consensus validation. Int J Clin Pharmacol Ther 2008;46:72-83.

19. O'Mahony D, O'Sullivan D, Byrne S, et al. STOPP/START criteria for potentially inappropriate prescribing in older people: version 2. Age Ageing 2015;44:213-8.

20. Chang $\mathrm{CB}$, Chan DC. Comparison of published explicit criteria for potentially inappropriate medications in older adults. Drugs Aging 2010;27:947-57.

21. Chang $\mathrm{CB}$, Chen JH, Wen CJ, et al. Potentially inappropriate medications in geriatric outpatients with polypharmacy: application of six sets of published explicit criteria. Br J Clin Pharmacol 2011;72:482-9.

22. Desnoyer A, Guignard B, Lang PO, et al. [Potentially inappropriate medications in geriatrics: Which tools to detect them?]. Presse Med 2016;45:957-70.

23. Lavan AH, Gallagher PF, O'Mahony D. Methods to reduce prescribing errors in elderly patients with multimorbidity. Clin Interv Aging 2016;11:857-66.

24. Viktil KK, Blix HS, Moger TA, et al. Polypharmacy as commonly defined is an Indicator of limited value in the assessment of drugrelated problems. Br J Clin Pharmacol 2007;63:187-95.

25. Longo D, Fauci A, Kasper D, et al. Harrisons principles of internal medicine. 18th ed, 2012.

26. Institute for Safe Medication Practices - ISMP List of High-Alert Medications in Acute Care Settings. 2014. http://www.ismp.org/ tools/highalertmedications.pdf (accessed 17 Jan 2017).

27. Budnitz DS, Shehab N, Kegler SR, et al. Medication use leading to emergency department visits for adverse drug events in older adults. Ann Intern Med 2007;147:755-65.

28. Boulkedid R, Abdoul H, Loustau M, et al. Using and reporting the Delphi method for selecting healthcare quality indicators: a systematic review. PLoS One 2011;6:e20476.

29. Prot-Labarthe S, Weil T, Angoulvant F, et al. POPI (Pediatrics: omission of prescriptions and inappropriate prescriptions): development of a tool to identify inappropriate prescribing. PLOS One 2014;9:e101171.

30. Patton MQ. Enhancing the quality and credibility of qualitative analysis. Health Serv Res 1999;34:1189-208.

31. World Health Organization. Process of translation and adaptation of instruments. Available from: http://www.who.int/substance_abuse/ research_tools/translation/en/ (accessed 17 Jan 2017).
32. Centre Belge d'Information Pharmacothérapeutique. Base De données DME, 2015. http://www.cbip.be/fr/download (assessed 17 Jan 2017).

33. Sécurité sociale, assurance maladie. La base des médicaments et Informations Tarifaires, 2015. http://www.codage.ext.cnamts.fr/codif/ bdm_it/index_presentation.php?p_site=AMELI (assessed 17 Jan 2017)

34. Health Canada. Drug Product Database. 2015. http://www.hc-sc.gc. $\mathrm{ca} / \mathrm{dhp}$-mps/prodpharma/databasdon/dpd_bdpp_data_extract-eng. php (assessed 17 Jan 2017).

35. Confédération suisse. Liste Des spécialités. http://www. listedesspecialites.ch/Default.aspx (assessed 17 Jan 2017).

36. Davey P, Brown E, Charani E, et al. Interventions to improve antibiotic prescribing practices for hospital inpatients. Cochrane Database Syst Rev 2013;4:CD003543.

37. O'Mahony D, Gallagher PF. Inappropriate prescribing in the older population: need for new criteria. Age Ageing 2008;37:138-41.

38. Howard RL, Avery AJ, Slavenburg S, et al. Which drugs cause preventable admissions to hospital? A systematic review. Br J Clin Pharmacol 2007;63:136-47.

39. Dalkey NC. The Delphi Method: an experimental study of Group Opinion. Santa Monica, CA: RAND Corporation, 1969. http://www.rand. org/pubs/research_memoranda/RM5888 (assessed 17 Jan 2017).

40. Gallagher PF, O'Connor MN, O'Mahony D. Prevention of potentially inappropriate prescribing for elderly patients: a randomized controlled trial using STOPP/START criteria. Clin Pharmacol Ther 2011;89:845-54.

41. Bloom BS. Effects of continuing medical education on improving physician clinical care and patient health: a review of systematic reviews. Int J Technol Assess Health Care 2005;21:380-5.

42. Keijsers CJ, van Doorn AB, van Kalles A, et al. Structured pharmaceutical analysis of the systematic Tool to reduce Inappropriate Prescribing is an effective method for final-year medical students to improve polypharmacy skills: a randomized controlled trial. J Am Geriatr Soc 2014;62:1353-9.

43. van der Hooft CS, Jong GW, Dieleman JP, et al. Inappropriate drug prescribing in older adults: the updated 2002 Beers criteria--a population-based cohort study. Br J Clin Pharmacol 2005;60:137-44.

44. Stevens MB, Hastings SN, Powers J, et al. Enhancing the Quality of Prescribing Practices for older veterans discharged from the Emergency Department (EQUiPPED): Preliminary results from enhancing Quality of Prescribing Practices for older veterans discharged from the Emergency Department, a novel multicomponent Interdisciplinary Quality Improvement Initiative. J Am Geriatr Soc 2015;63:1025-9.

45. Bradley MC, Fahey T, Cahir C, et al. Potentially inappropriate prescribing and cost outcomes for older people: a cross-sectional study using the northern Ireland enhanced Prescribing Database. Eur J Clin Pharmacol 2012;68:1425-33.

46. Bongue B, Laroche ML, Gutton S, et al. Potentially inappropriate drug prescription in the elderly in France: a population-based study from the French National Insurance Healthcare system. Eur J Clin Pharmacol 2011;67:1291-9.

47. Agency for Healthcare Research and Quality (AHRQ) - National Healthcare Quality Report. 2012. Available at: archive.ahrq.gov/ research/findings/nhqrdr/nhqr12/2012nhqr.pdf

48. National Committee for Quality Assurance. Proposedchangestoexisting measurefor HEDIS $® 1$ 2016: Medication Reconciliation Post-Discharge (MRP), 2015. http://www.ncqa.org/ Portals/0/PublicComment/HEDIS2016/10. Medication Reconciliation Post-Discharge.pdf (accessed 17 Jan 2017).

49. Hamilton $\mathrm{H}$, Gallagher $\mathrm{P}, \mathrm{Ryan} \mathrm{C}$, et al. Potentially inappropriate medications defined by STOPP criteria and the risk of adverse drug events in older hospitalized patients. Arch Intern Med 2011;171:1013-9.

50. Erkut S. Developing multiple language versions of Instruments for Intercultural Research. Child Dev Perspect 2010;4:19-24.

51. Shekelle PG, MacLean CH, Morton SC, et al. Assessing care of vulnerable elders: methods for developing quality indicators. Ann Intern Med 2001;135:647-52. 